THE "ITALIA" AIRSHIP.

An Italian inventor, Count Almerico da Schio, while convinced of the superiority of the " thathair" hip to be the best meins of teaching men the art of navigating the air. The Count thinks it best, therefore, to reject the airship only after man shall have learned to move safely through the air with a balloon to supplement the floating power and stability of the flying machine proper.

The new "Italia" airship is accordingly designed as a complete flying machine including wings, propellers, and rudder, the balloon being made to fulfill the secondary function just referred to, and to become more and more reduced so as eventually to disappear as the flying machine proper is continually improved. The disadvantages common to most batloons of losing ballast in rising and gas in descending, are remedied by using the motor and aeroplanes exclusively for rising and descending. This will allow the airship to remain longer in the air, and will make it able at any time to seek for the most favorable air currents.

The airship "Italia" constructed by Count da Schio, as can be seen from the photograph, is cylindrical in

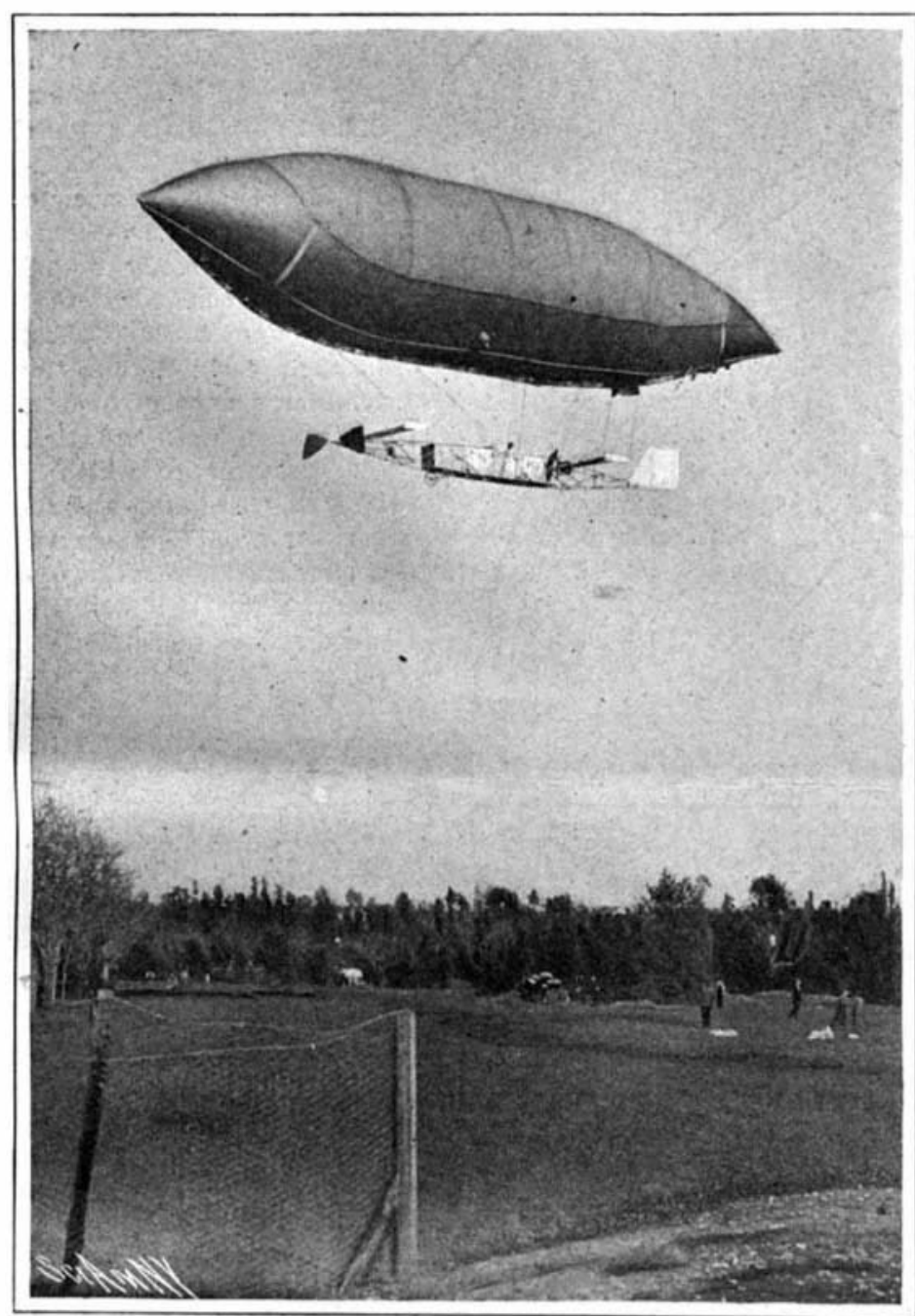

The "Italia" Airship in Flight.

the middle, throughout a length of 10.3 meters (42.64 feet), the diameter being about 8 meters (261/4 feet). The front part, 11 meters (36.08 feet) in length, re sembles the point of a shrapnel, and the much thinner

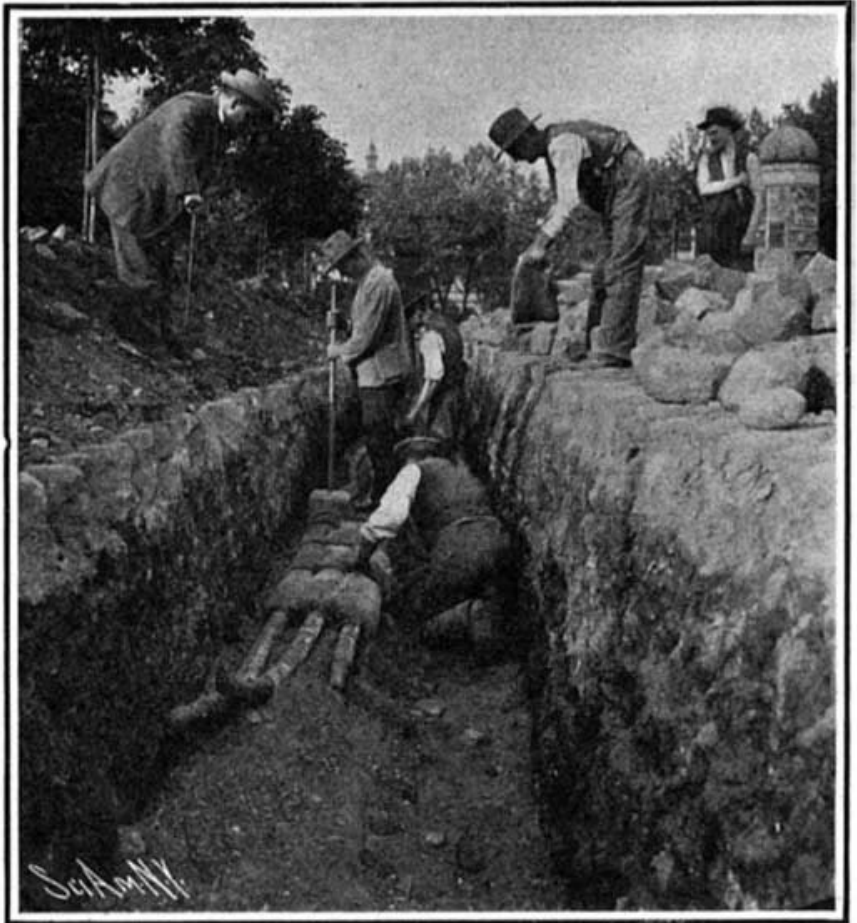

Preparing the Protective Sheath.

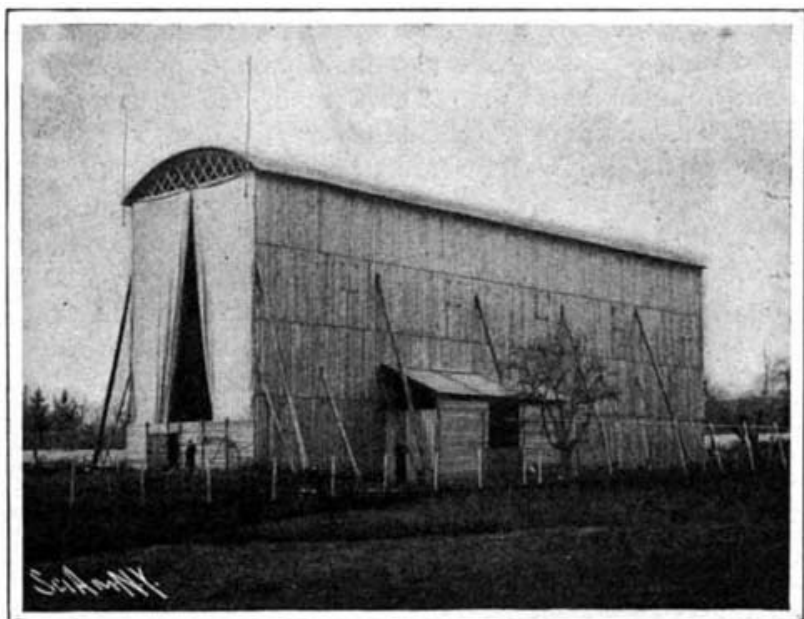

The Bnilding in Which the Airship is Housed.

rear part is about 16.4 meters (65.61 feet) in length The cover consists of varnished Italian silk coated outside with aluminium powder to reduce the effects of itght. The regular symmetrical shape of the bottom of the balloon is obtained by coating the lower portion rof the cover with highly elastic India rubber such as is used by Prof. Hergesell in connection with his "ballons-sondes." As this part is extremely elastic (it can be stretched to four times its original length) the cove will always be uniformly tightened, an the balloon will maintain its regula shape with a volume varying according to the atmospheric pressure. The horizontal aeroplanes having surfaces of 10 square meters (107.64 square feet) each, used in rising and descending, augment the longitudinal resistance of the airship. The frame is provided with three wheel and pneumatic tires to facilitate its manipulation on land.

Only a few preliminary experiments have so far been made with the Schio airship, in which King Umberto and the Dowager Queen Margherita are takin much interest. While the results so far obtained would seem to bear out the claims made by Count Schio, judgment should be reserved till the definite experiments which are to take place shortly have been made.

\section{THE LAYING OF A 10,000-VOLT CABLE.}

It is due to the high insulating power of atmospheric air that most electrical phenomena come at all to our notice. The same property of air proves very valuable in electrical engineering by allowing current-carrying conductors to be strung out in the open without the risk of leakage, provided there be no possibility of eithe a short circuit or a ground. These overhead conductors possess the advantage of being extremely cheap and casily inspected, but they are exposed to various dangers, rendering them unre liable for use in large cities. Here not only the risk as well, are urged against this type of conductor, and for these reasons cables are usually substituted for bare overhead wires. These cables consist of insulated copper conductors, either single or in sets of two or more; and in order to protect them from injury, and prevent the current they carry from doing any damage, they are buried in trenches.

We are indebted to the Berlin Electricity Works for the accompanying illustrations, showing the recent operation of laying a 10,000 -volt cable. The line is intended for transmitting current generated at the Oberspree central power station to the Zossenerstrasse and Alte Jakobstrasse sub-stations. The cable was constructed at the Oberschöneweide Cable Works of the Allgemeine Elektrizitäts-Gesellschaft. It is to carry three-phase current, and accordingly comprises three copper strands of 1.085 square inches cross section each. Each of these conductors, on account of the high pressure carried, is at first surrounded with a caoutchouc layer, and together with the two others is imbedded in jute. Around this insulation a lead sleeve is forced, and this Arrves to exclude moisture. Over the sleeve is a wrapping of jute, and on this an iron sheathing is wound. The cable was made in lengths of about 170 meters ( 557.7 feet) each and coiled on wooden drums. It was carried to the working place in special cars. The trench in which the cable was to be aid was dug ' to a depth of three feet. After running out the drum from the car, it was taken to the head of the trench, and a of thorkmen seizand carried it on their should ers into the trench. Here it was dropped into specially arranged rollers, by means of which it was from the rum This done, the cable was straightened and provided at intervals with labels indicating its cross section, the voltage it was adapted to carry, quired strand might be readily identified in case of future repairs. As the iron sheathing referred to above could ull protection to the high - tension conduc tors, the cable was coated with a concrete 1 a y e r. The concrete was placed in rough jute bags, which were
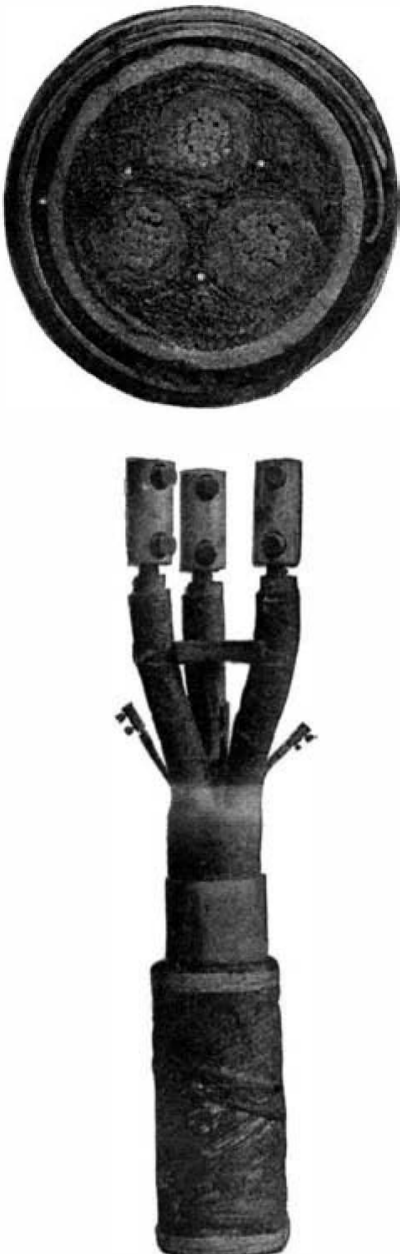

Sections of High-Tension Cable. amped down on the

cable throughout its length. The jute bags soon gave way, permitting the concrete to set over the upper half of the cable, and thus provide it with a solid concrete covering. The trench was then "filled in. The joints

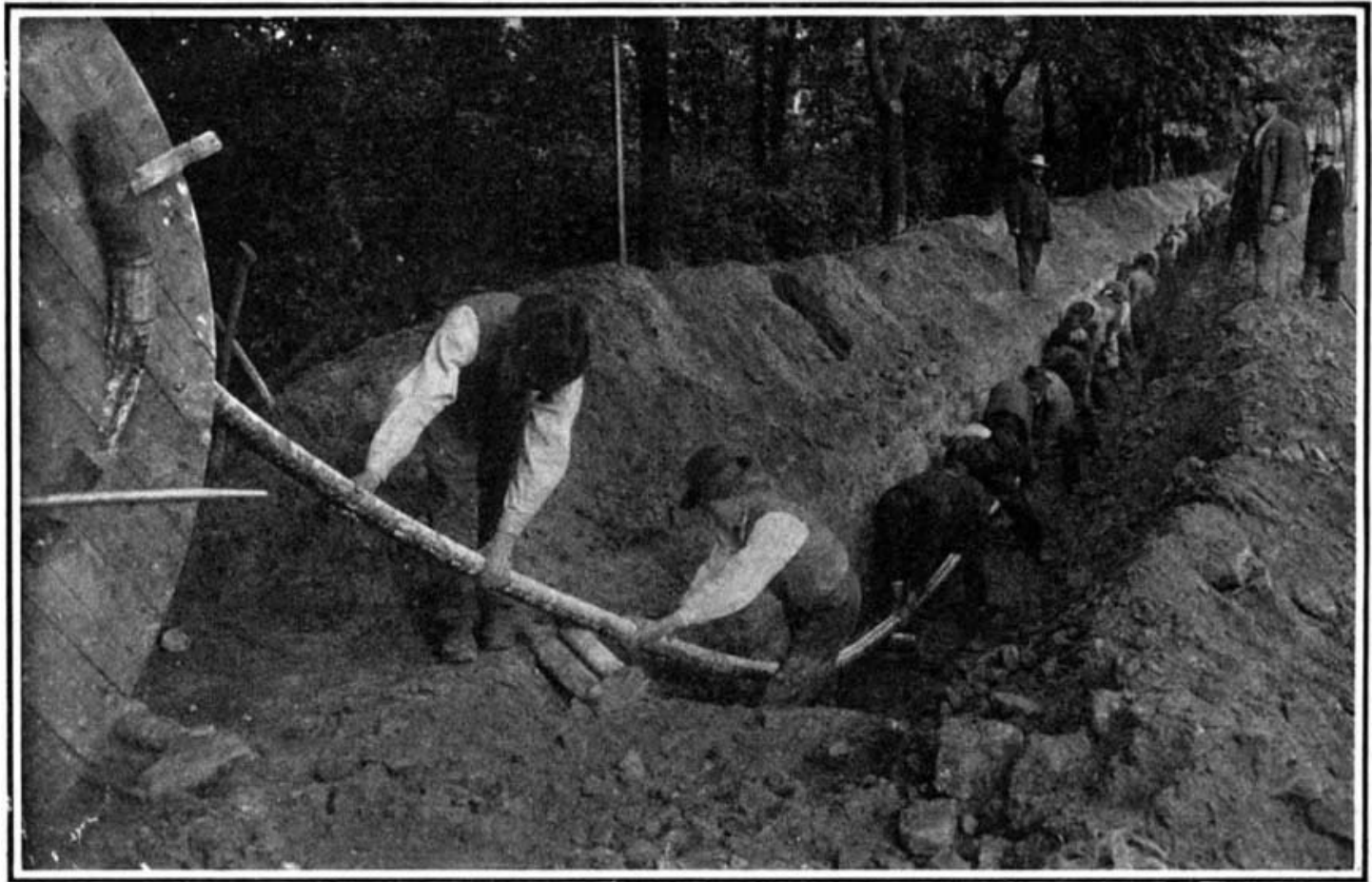

Laying the Cable in the Trench. 
between the cable sections and the mains were protected by iron sleeves locked in place by setscrews, after which the sleeves were filled with an insulating substance. These operations, requiring a great amount of attention and accuracy, were carried on under a tent to guard against moisture and other disturbing factors.

As a perfect insulation of the cable is of vital im portance in this work, each of the sections buried in the trenches was immediately submitted to certain tests. The apparatus for this purpose was arranged in a special cable-measuring car, which was conveyed by hand along the cable line, and by means of which the necessary observations were carried on in a minimum of time. To provide for future measurement of the voltage, etc., obtaining at the terminals of the cable, each conductor is provided with a testing wire, the diameter of which is obviously quite small. In one of our illustrations the three testing wires may readily be seen beside the main conductors At the crossing of the cable line with the Goerlitz Railway, iron pipes receiving the cables were fitted at a depth of three feet below the ties. Seven such cables were laid during last summer, following a common course as far as Vienna bridge, whence they branched off in three strands to the Zossenerstrasse sub-station, and in four strands to the Alte? 2 kobstrasse sub-station.
MAKING THE FLAGS OF OUR WARSHIPS.

Through the courtesy of the Commandant of the Brooklyn navy yard and Commander A. Ward, chief equipment officer, the writer was given special opportunities for obtaining a full series of pictures showing an interesting and comparatively littleknown department in which the flags of our warships are made. The flag room is under the supervision of Mr. Thomas Malloy, officially rated as master flagmaker, and Miss M. A. Woods, quarter-woman flagmaker. Mr. Malloy favored the writer with all the main details of the flag department, which are out lined in the present narrative.

To furnish the many hundreds of naval vessels in commission, ranging from the large flagship and battleships and the numerous smaller class, with their regular quota of flags, the government is required to maintain an extensive plant. Few, however, realize the number of flags carried by a warship, nor the cost of all the gay bunting which flutters from mast to mast at holiday time. In addition to fleet communication, necessary during all forms of maneuvers in home waters, the ship must be equipped with an extensive array of flags stored on board for various forms of ceremonial and official occasions. This "dress suit" outfit of bunting, therefore, consists of
250 different flags, the material and making of which costs Uncle Sam just $\$ 2,500$. Each ship is entitled to a new flag equipment every three years, though a flagship will often require a new set of signals, owing to their constant use and handling in about a A striking idea of the number of flags carried by a single ship may be gleaned from one of the accom panying illustrations, showing a pile 15 feet long and nearly waist high, just finished for the new battleship "Connecticut." About one-half of the lot is composed of foreign flags, incased in thick paper bags, with the name of the country stenciled on the bottom. The remainder, including those for ordinary use signal sets, and the international code etc, are not wrapped, but merely tied in round bundles. Last year for operating the flag factory the government expended $\$ 60,000 ; \$ 43,000$ of this amount was for material alone. This, however, includes a small sum for table linen and curtain fixtures; the labor amounted to $\$ 17,000$. The number of flags turned out was over 59,000 . In all, 408 distinctive kinds were made. To cut out the varied patterns and complete all these miscellaneous flags, some thirty-five skilled machine sewers and needle-women and three men are employed.

With the bright-colored, fantastic flags of all nations dangling from their machines, the long row of flag

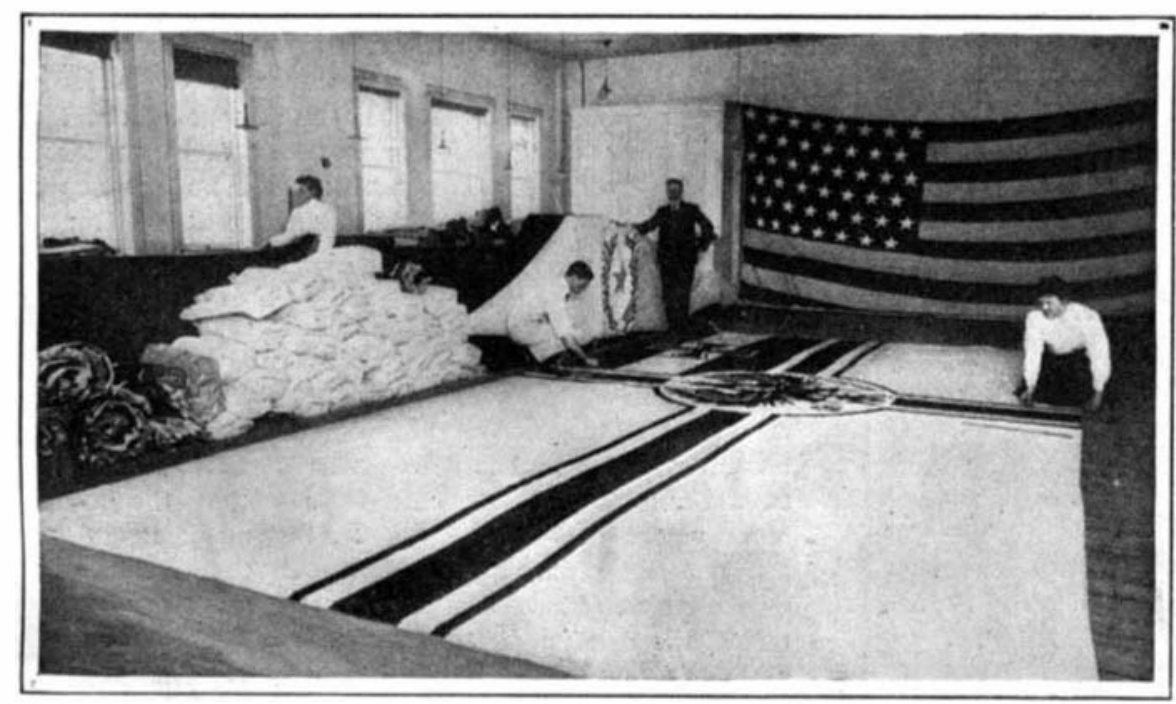

Finishing the German Ensign, the Mlost Expensive One Made.

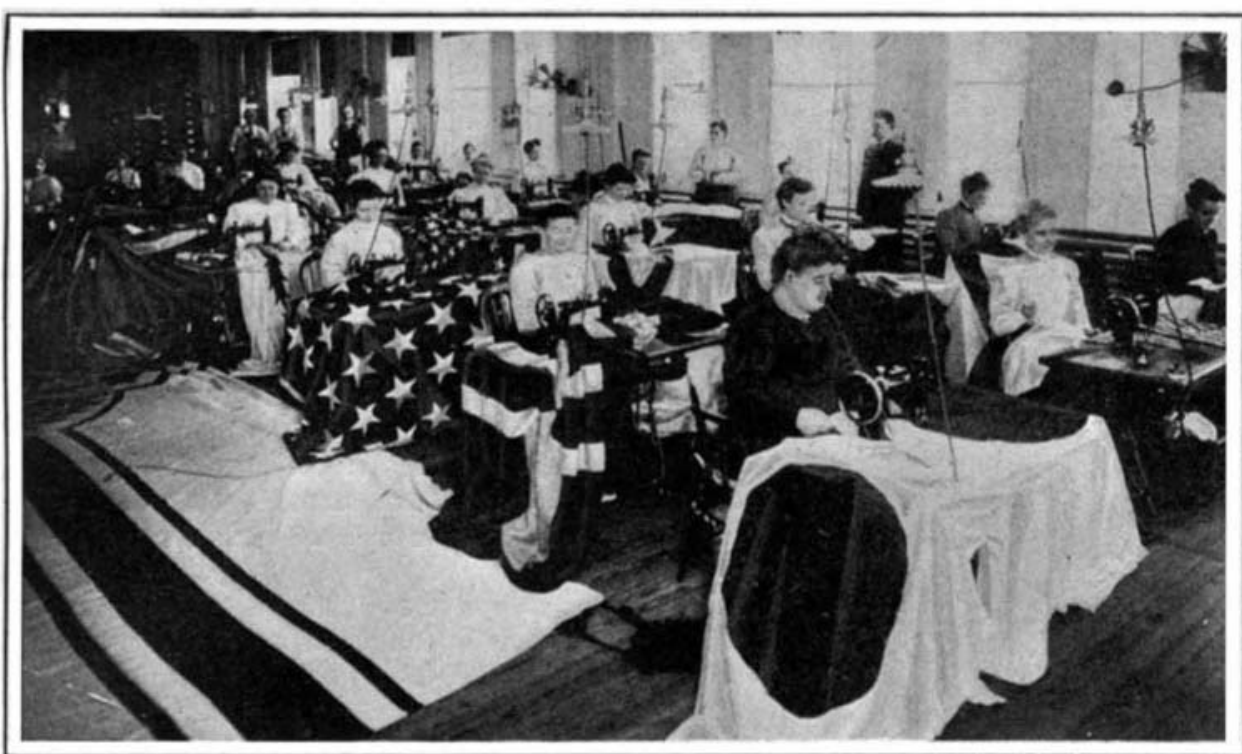

One of the Main Rooms of the United States Flag Factory at the Brooklyn Navy Yard.

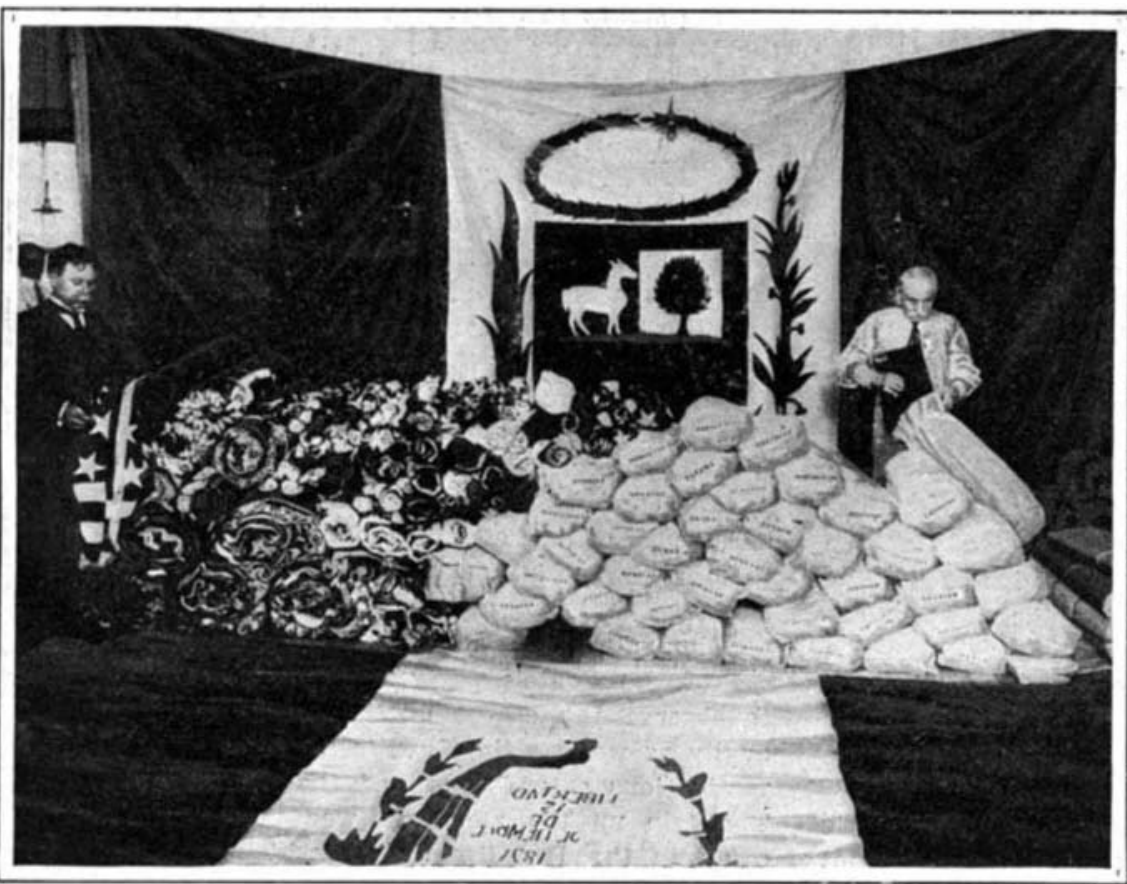

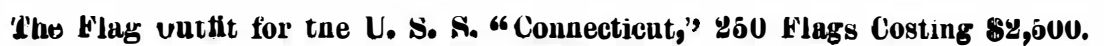

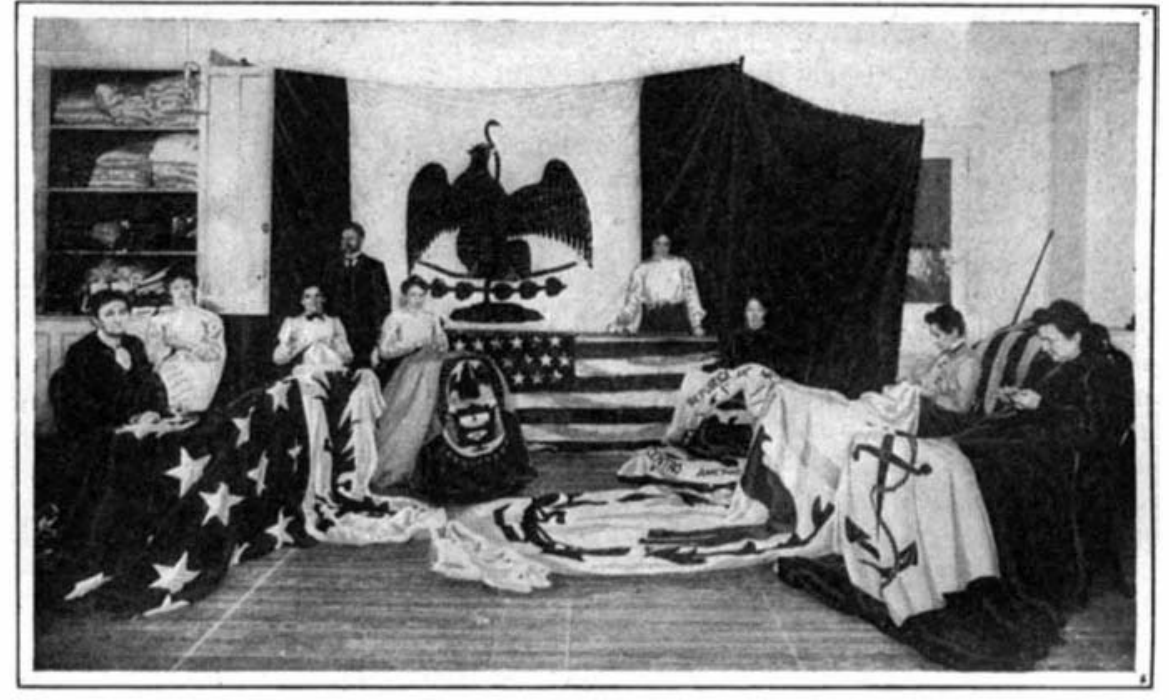

The Hand Sewers Who Execute the More Difficult Designs.

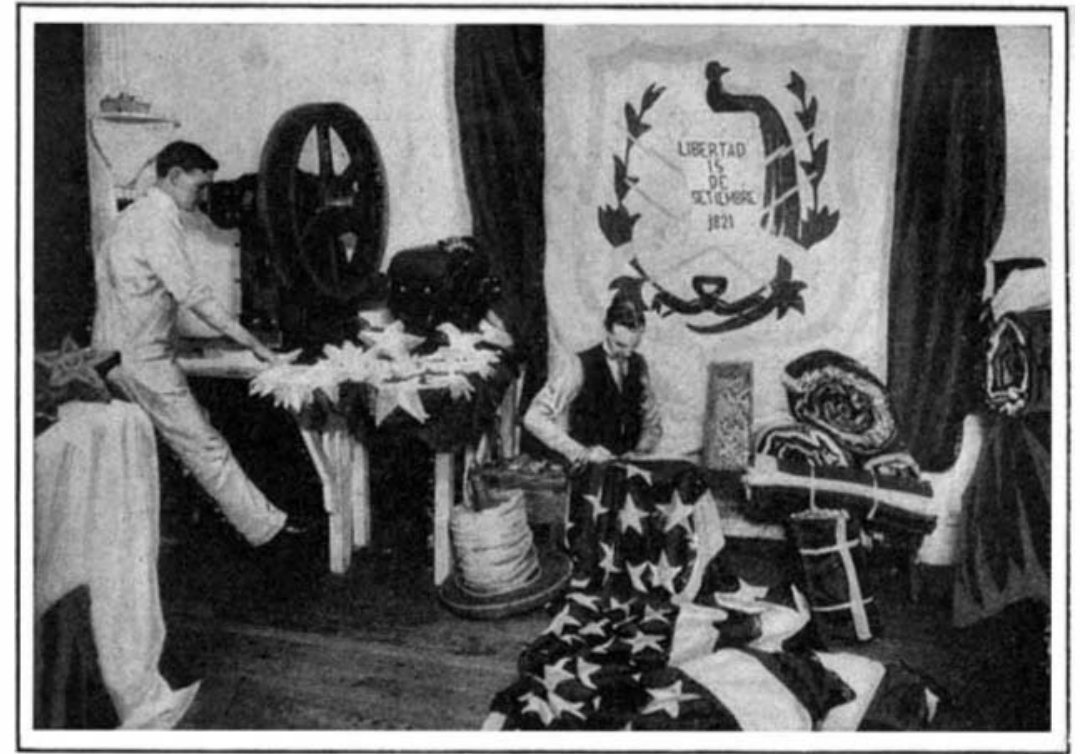

The Star Cutting Machine; Sewing On a Halyard Bend.

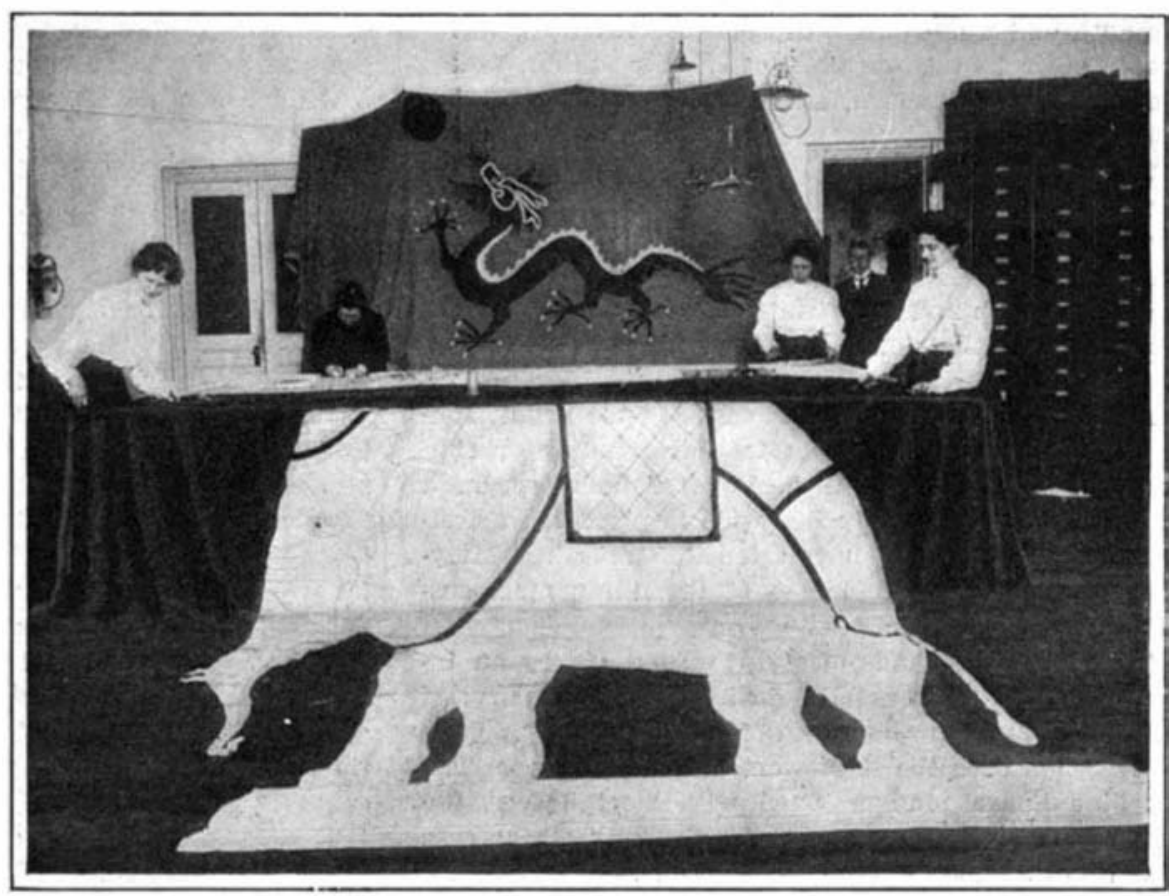

Cutting Out Patterns; the Flags of China and siam Above and Bulow the Table. MARING THE FLAGS OF OUR WAKSIIPS. 